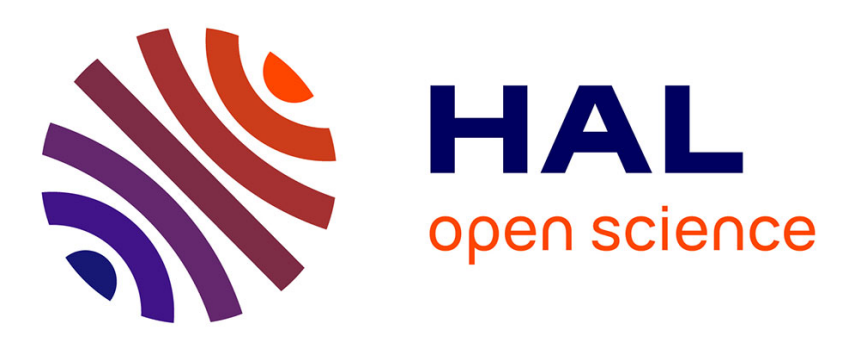

\title{
Box/Lockers' contribution to Collaborative Economy in the Smart City
}

Bertrand T. David, René Chalon

\section{To cite this version:}

Bertrand T. David, René Chalon. Box/Lockers' contribution to Collaborative Economy in the Smart City. 2018 IEEE 22nd International Conference on Computer Supported Cooperative Work in Design (CSCWD 2018), Southeast University, China, May 2018, Nanjing, China. pp.802-807, 10.1109/CSCWD.2018.8465151 . hal-01829111

\section{HAL Id: hal-01829111 \\ https://hal.science/hal-01829111}

Submitted on 3 Apr 2019

HAL is a multi-disciplinary open access archive for the deposit and dissemination of scientific research documents, whether they are published or not. The documents may come from teaching and research institutions in France or abroad, or from public or private research centers.
L'archive ouverte pluridisciplinaire HAL, est destinée au dépôt et à la diffusion de documents scientifiques de niveau recherche, publiés ou non, émanant des établissements d'enseignement et de recherche français ou étrangers, des laboratoires publics ou privés. 


\title{
Box/Lockers' contribution to Collaborative Economy in the Smart City
}

\author{
Bertrand DAVID, René CHALON \\ Université de Lyon, CNRS, \\ Ecole Centrale de Lyon, LIRIS, UMR5205, \\ F-69134 Ecully Cedex, France \\ \{Bertrand.David, Rene.Chalon \}@ec-lyon.fr
}

\begin{abstract}
Box/Lockers, one approach for delivery of purchased goods, can play an interesting role by supporting Collaborative Economy. Our goal in this paper is to examine the relationship between CSCW and delivery approaches in order to facilitate collaborative economy by applying uberization techniques. The role of intermediation and of the intermediation platform is also presented.
\end{abstract}

Keywords-CSCW, Groupware, uberization, purchasing approaches; intermediation; intermediation platform

\section{INTRODUCTION}

Nowadays, a variety of purchasing strategies are available for shopping. The classical physical approach based on the shopper (physical movement to the shop and physical transportation of purchased goods) can be replaced by the totally virtual solution of e-commerce and the associated delivery service. Several mixed solutions are also possible, in which either the purchase or delivery part of the process is carried out virtually or by another actor. Collaborative economy is a way of sharing appropriately different proposals of goods and potential buyers in order to allow all actors to benefit from this collaboration. Provision of a means that can connect these two categories of actors is a major issue.

Our goal is to examine in which way CSCW and collaboration systems can contribute to this trend. As cooperative / collaborative systems are intended to allow a group of actors to carry out their activities appropriately, it is by combining the functionality of integration and cooperation and by adding new functionalities as intermediation that an appropriate support system can be proposed.

\section{SHOPPING APPROACHES IN THE SMART CITY}

In the Smart City approach [1, 2, 3] of in-city life, old and new shopping and distribution techniques are used for different products (documents, goods and foods) [4]. A number of new constraints are progressively taken into account: the main ones are rapidity (distribution time), security (during transportation and delivery), thermal conditions, as well as ecological conditions (traffic, noise, environmental pollution). Generally, it is useful to distinguish between $\mathrm{B} 2 \mathrm{~B}$ relationships in which provider and receiver are professional, and $\mathrm{B} 2 \mathrm{C}$ and $\mathrm{C} 2 \mathrm{C}$ relationships when the receiver is not a professional but an individual client who is not available all the time at his/her address. The process may also include a non-professional actor, provider, organizer or deliverer. These situations can considerably influence the delivery process and performance.
For receivers available all the time, the distribution process is easier, as it is considered that single, first, distribution is successful. For sporadically available receivers, several deliveries are often required, thus increasing delivery cost and decreasing profitability. Delivery subcontracting and alternative solutions are proposed: a more precise relationship between deliverer and receiver based on establishing a meeting time or finding an external solution such as a delivery point or locker.

From performance and ecological points of view, individual delivery of parcels, by different delivery trips and vehicles, contributes to the creation of traffic jams and harmful particle emission. More appropriate solutions are emerging known as "massification" (grouping all parcels for the day or week for a receiver) aimed at minimizing the number of trips, and "mutualization" (giving one delivery firm an area of distribution). The delivery area reservation process is another solution for increasing delivery performance [5].

If we analyze clients' shopping behaviors, we can identify the following four situations:

1) Classical physical shopping: go to the shop, choose, collect, pay and transport the corresponding goods to your home;

2) Physical choice and home delivery: go to the shop, choose, collect, pay and ask for delivery to your home;

3) Drive: choose and order by Internet and go to collect the goods at the delivery place (often the shop drive platform);

4) eShopping: choose and order by Internet and receive the ordered goods at home (or other address) by the shop delivery service.

As we mentioned above, delivery to sporadically available receivers is a major problem affecting the profitability of this delivery process. Drive is a possible solution (avoiding at home access availability). The recently proposed Amazon Key InHome Kit is a potential solution, which requires the deliverer to have complete trust.

We are currently studying a less constrained solution based on proximity located Box/Lockers and their use in an open situation, allowing them to be shared between several providers. They can thus support collaborative economy.

\section{COLLABORATIVE AND SHARED ECONOMY: UBERIZATION}

The term "uberization" is a neologism popularized by Maurice Lévy after an interview with the Financial Times in 
December 2014. The term originates from the Uber Company that has globally popularized passenger cars with driver, thus competing directly with taxis. The features of this service are almost real time, pooling of resources and the small percentage of heavy infrastructure (offices, support services, etc.) in the cost of service. This term "uberization" is generally used to refer to the phenomenon whereby a start-up or a new economic model related to the digital economy threatens to replace an old economic model. Some of the services mentioned the following examples: Airbnb, Booking.com and Amazon. After the two models, Uber and Uber Pop, which are currently challenging traditional $\mathrm{Cab}$ activity, the car share BlaBlaCar Company, initially created in France, is another uberized model for transportation sharing.

The collaborative/shared economy is understood in a broad sense, including collaborative consumption (couchsurfing, carpooling etc.) but also shared lifestyles (coworking, colocation, collective housing), shared finance (crowdfunding, ready to silver peer-to-peer, alternative currencies), contributory output (digital manufacturing, DIY, Fablabs, 3D printers, maker spaces) and free culture.

It assumes different forms (sharing economy, service economy including circular economy, economy of solutions, peer-to-peer economy according to the types of goods and services concerned or proposed (consumer empowerment, ecoeffectiveness). This kind of economy is placed in a context of mistrust of institutional actors in the traditional capitalist system and in an economic crisis context, as well as in an ethical and environmental context.

Its rise is due to the use of new technologies to improve collective/shared creativity and productivity. It also responds to the desire for green practices and more friendly social relations.

\section{A. CSCW versus Uberization}

$\mathrm{CSCW}$ is, historically, computer supported collaboration and cooperation between several actors (identified or anonymous) $[6,7,8]$. They can work locally (at the same place) or at a distance (in different locations) and synchronically (at the same time) or asynchronously (at different times) and share data, which can be modified by each actor, with respect to his/her role in the work organization, called workflow.

Uberization is defined as cooperation between consumers and providers using a cooperation/sharing platform. In this context, consumers and providers are individuals (proposing and requesting use of a service).

In [9] we compared CSCW applications with Uberized applications and observed that the latter are mainly short-term oriented and limited to establishing a relationship between provider and consumer intermediated by the platform. We can conclude that uberized activities can use all the main components and services proposed by $\mathrm{CSCW}$ and the associated software (groupware). However, it is important to point out that new services are mandatory for uberization. These services are mainly related to intermediation, which is able to manage the relationship between, usually, a pair of actors (provider and consumer). This intermediation service, which Choudary has called the Matchmaker [10], has at its disposal a large amount of information either in real time or collected in the past, by means of appropriate selection techniques and algorithms based on Big Data and data mining algorithms. It thus seems more appropriate to create an uberization oriented Platform by upgrading a Collaborative Platform than to develop an Uberization Platform from scratch and apply what is known as crosspollination between groupware and uberware.

\section{B. Intermediation platform or service}

Intermediation platforms connect people, services and even things in ways that have been unthinkable until now. Search engines provide relevant references for people searching for information. Social networks connect users in their environment. Carpooling systems link drivers and passengers whose goal is to take the same routes. Intermediation platforms use big data to fuel the services they offer. All intermediation platforms essentially rely on the same structure. At the beginning they collect huge amounts of data which can derive from the outside world (e.g., web pages for search engines) or are hosted by the platform (e.g., social networks). However, they are not necessarily produced by the platform itself but rather by the people, services or things around it. These primary data are then indexed and transformed to extract information that fuels the primary services offered.

Users' activities on the platform generate secondary data. These secondary data mainly consist of traces that the platform generally has exclusive rights to use as well as to create secondary services. A key example of this is the precise profiling of users, which allows personalized and customized services: personal assistants trace users as they go about their day-to-day activities, not only on-line but also in the physical world through the use of geo-localization or quantified-self means.

Let us now return to Box/Locker based distribution and its use in supporting Collaborative Economy.

\section{BOX/LOCKER BASED DISTRIBUTION}

\section{A. Classical box/lockers}

A new type of distribution solution emerged recently. Its goal is to provide a location for storing parcels outside the final destination. This avoids non-delivery if the receiver is absent, leading to a new delivery trip at another time of the day or the next day. In this way, an asynchronous behavior between transporter and receiver is created.

The Box/Locker is generally located in a public area. This solution is commonly used for postal parcels and letters, i.e. the French Post uses it, as well as the Chinese Post for B2B and $\mathrm{B} 2 \mathrm{C}$ distribution schemas. Today, this solution is also used for distribution of different goods such as foods, mainly in the B2C schema. It has been implemented recently by a number of supermarkets such as Casino, which provide this kind of box/locker in front of their stores. One of the main providers of this solution is InPost, a Polish company providing its solution worldwide (Canada, France, etc.) [12]. 
The advantage of this kind of Box/Locker is its availability in multiple areas of the city or town, as well as in pedestrian areas: it is also called a "pedestrian drive", in reference to super and hypermarket drives for vehicles. Its main advantage is its accessibility 24 hours a day 7/7 days a week. The location is carefully chosen to optimize proximity for pedestrians and accessibility for loading.

The standard physical structure is a big cupboard with, at the user-oriented face, a large number of slots each receiving a letter or parcel. An interactive screen is used to manage control and access commands for providers (loaders) and receivers (retrievers), based on access codes for both parties. The user interface is either based on tactile interaction on a Box/Locker screen or can be deported to the user's smartphone.

Bingobox [12], managed by the WeChat social network, is another concept of a "fresh food" $100 \%$ automated shop without staff allowing the client to choose freely the goods that he/she purchases. This is a Canadian "depanneur" store, which can be moved to different locations in the city. Amazon Go [13] has the same characteristics. This concept is totally different from the box/locker concept.

ByBox [14, 15] is a more directly related proposal, hailing from the Silicon Valley and created in February 2000. The original mission was to build technology to increase the efficiency of online shopping delivery. The first product was an electronic lockerbank connected to the Internet. Today, ByBox continues to lead the global market for locker-based solutions to difficult supply chain problems. Online shopping remains a core market for ByBox with a range of automated Click \& Collect solutions. Today, the three pillars of ByBox are software, technology and infrastructure. A ByBox proprietary software platform was designed to re-wire field service supply chains to operate with less inventory and minimal distribution, with the mantra "move the data, not the part". For field service, the latest product is an app-controlled smart box, which takes the form of temperature controlled units for the grocery market. The ByBox is used in the UK and South Africa.

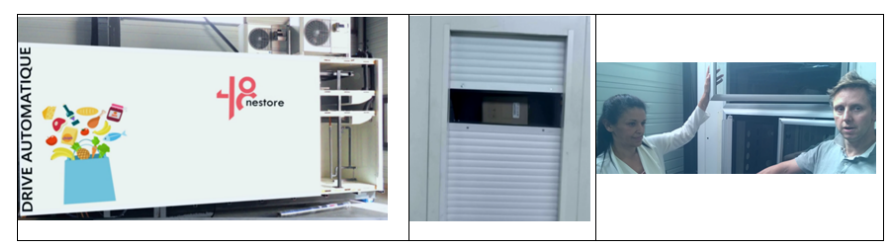

Fig. 1. Box/Lockers for fresh and frozen foods

\section{B. Box/Lockers for fresh and frozen foods}

We designed and developed in a consortium of several companies and academic institutions, a new Box/Locker concept, which aim is to store and deliver foods at the appropriate temperature [16]. This physical structure is different in order to avoid temperature loss due to coolness (Fig. 1). We replaced multiple slots and their associated doors by a single door able to open to match with the vertical location of baskets containing parcels. In other words, the parcels are not statically located in slots but in baskets with several slots. The vertical position of the slot is related to the corresponding temperature (ambient, fresh or frozen). The baskets move circularly in the Box/Locker to be positioned in front of the door during storage (by the provider) or retrieval (by the receiver - client).

Usually three kinds of physical location can be used for these Box/Lockers as follows:

1) In front of a store,

2) In a shopping mall or railroad station,

3) Outside the town or city.

24 hour and 7/7 day availability for clients-receivers is the main characteristic. The first statistics collected by InPost are very interesting. $30 \%$ of goods are retrieved during the weekend and $32 \%$ at night (between 8pm and 9am). Another advantage concerns the providing / loading process, which can take place according to provider working and transportation conditions, independently from the retrieving process (asynchronously).

In the first case (in front of the store), the providing process can be continuous during store opening hours. For distant locations (malls or outside towns/cities) the decision to provide depends on the distance and the amount of parcels to transfer. Optimization is necessary between a high degree of reactivity (often demanded by clients) and the transportation cost / quantity of parcels to provide. This aspect requires appropriate data analytics to discover behaviors in the field and take them into account for Box/Locker functioning.

\section{Box/Lockers for fresh and frozen food software architecture}

Our main goal is to study the role of the Box/Locker in different working situations on the market. For this purpose, we present, first, generic software and then its adaptation to different market environment configurations.

This kind of locker is generally used in the following scenario. The user (shopper) connects to the website of his/her preferred shop - super or hyper market, selects and orders appropriate goods and dry, frozen or fresh foods (needing temperature controlled storage). He/she also selects the location of the preferred Box/Locker and the required date and time of availability.

The website registers this order and payment and transfers the order to the logistic department, which is in charge of preparing it and organizing its transportation to the Box/Locker. An email or SMS is sent to the client as promptly as possible to give him/her the availability date and time of the order in the chosen Box/Locker. A logistician/provider is in charge of transferring the goods to the Box/Locker and inserting them into it. To this end, the Box/Locker manager provides appropriate slots to be used. The goods (foods) needing different temperatures are located in the appropriate slots. Once the process is complete, a confirmation is sent to the client indicating that the order is available in the expected Box/Locker.

The main modules used to manage this process are: 
1) Website based order management, payment and order transfer to the logistician,

2) Order preparation and packaging, transportation scheduling and delivery,

3) Box/Locker local management with the loading (storage) and retrieving process, as well as the security, maintenance and cleaning actions,

4) Multi Box/Locker manager allowing more efficient scheduling of goods allocation if authorized by the user.

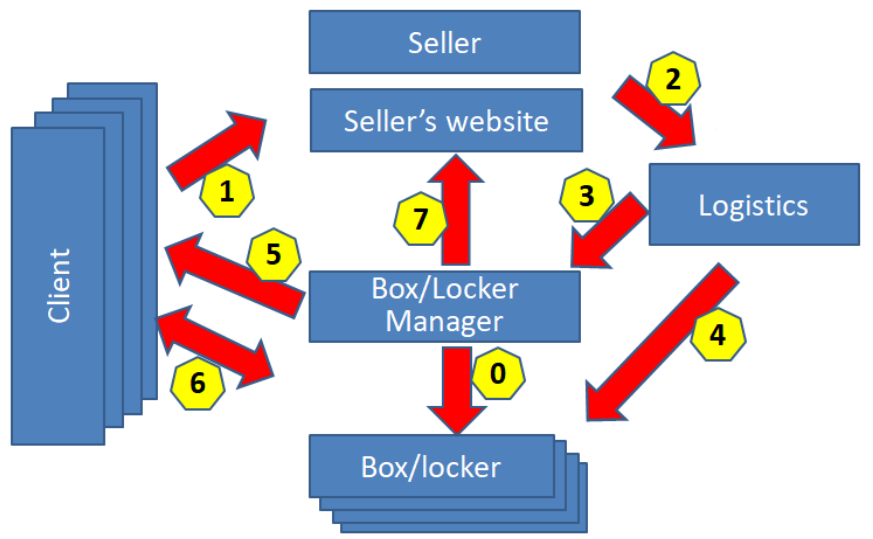

Fig. 2. Software architecture with main modules and exchanges.

The main exchanges between modules are (Figure 2):

0 - Management of multiple Box/Lockers: To know the current occupancy of each Box/Locker, basket and slot in order to allow the logistician to distribute appropriately the goods/foods on an order list. Management of forgotten items is also necessary.

1 - Client order list elaboration process via seller website.

2 - Transmission the order list to the logistician in order to allow him/her to prepare the corresponding delivery.

3 - Asking the Box/Locker manager to receive the Box/Locker identifier and baskets and slots for goods/food ordering.

4 - Transportation to and loading in the chosen Box/Locker of ordered goods, with the provider access code.

5 -Client information on goods availability (Box/Locker identifier, date and time of availability, and access code).

6 - Retrieval operation process based on the access code and the list of goods provided and their location in one or more baskets and slots used in ordering door opening and internal motion of baskets.

7 - Acknowledgement of completion of the loading or delivery operation, with, if necessary, a retrieval report sent to the seller.

The data manipulated, categorized by stakeholders involved in the information system, are:

1) Customer purchases: Identification of the customer, date of availability, location; List of products (nature, weight, volume, price)
2) Logistician: Shopping list; Separation by nature (packing): determined number and types of baskets to be provided;

3) Manager of the Box/Locker: Availability of baskets in each Box/Locker; Updating by exchange of information between manager and Box/Locker, Static reservation (on actual availability) or dynamic (overbooking)

4) Delivery man: List of deliveries by Box/Locker; List of customers and their slots; Inform the merchant site or the Box/Locker manager about implementation of the sales order, the latter informs the customer

5) Client retrieval: Access code, location, availability period, number of slots; Incident management

6) Maintenance technician: List of problems; Actions to be carried out; Report to the Box/Locker manager: baskets out of order, etc.

\section{BOX/LOCKER SUPPORTED COLLABORATIVE ECONOMY}

\section{A. Classical configuration: one provider for multiple users}

The first configuration is a classical one with several clients, one seller, one logistic provider, several Box/Lockers, one Box/Locker manager, and one final client (receiver) out of several as shown in Fig. 2. This can be formalized by the code Nc:1:1:1:Nlb:1:1/Nc (Table 1). In this basic configuration, we can consider that a single stakeholder is a seller providing his/her website and associated logistic services in a classical B2C schema. He/she can also be the owner of the Box/Locker infrastructure and its management. More usually, the Box/Locker infrastructure is owned and managed by another stakeholder. This separation between selling and providing goods on the Box/Locker infrastructure is a starting point for a more general distribution of roles and actors. One of these is based on the separation between selling and logistic services in charge of preparing and loading goods in the Box/Locker, directly derived from the seller's providers. In this case we have a B2B2C schema. This first elementary distributed solution can be increased in different ways, either by the number of independent services or by the number of actors for each one. We thus obtain a collaborative economy approach.

TABLE I. STAKEHOLDERS OF SELLING - DELIVERY SCENARIOS

\begin{tabular}{|l|l|l|l|l|l|l|}
\hline Client & Seller & $\begin{array}{c}\text { Seller's } \\
\text { website }\end{array}$ & $\begin{array}{c}\text { Logis } \\
\text { tician }\end{array}$ & $\begin{array}{c}\text { Box / } \\
\text { Locker }\end{array}$ & $\begin{array}{c}\text { B/L } \\
\mathbf{M n g r}\end{array}$ & Consumer \\
\hline $\mathrm{Nc}$ & 1 & 1 & 1 & $\mathrm{Nbl}$ & 1 & 1 of $\mathrm{Nc}$ \\
\hline $\mathrm{Nc}$ & $\mathrm{Ns}$ & 1 & 1 & $\mathrm{Nbl}$ & 1 & 1 of $\mathrm{Nc}$ \\
\hline $\mathrm{Nc}$ & $\mathrm{Ns}$ & $\mathrm{Ns}$ & $\mathrm{Nl}$ & $\mathrm{Nbl}$ & 1 & 1 of $\mathrm{Nc}$ \\
\hline $\mathrm{Nc}$ & $\mathrm{Ns}$ & 1 & $\mathrm{Nl}$ & $\mathrm{Nbl}$ & 1 & 1 of $\mathrm{Nc}$ \\
\hline
\end{tabular}

\section{B. Different collaborative economy configurations}

The goal of collaborative economy is to offer the possibility for several stakeholders to participate in the selling and delivering process, proving appropriate contributions. Three clearly characterized solutions can be identified:

Nc:Ns:1ws:1:Nlb:1:1/Nc - several clients, several sellers using a single website, one common logistician, several Box/Lockers with one Box/Locker manager and one final client between Nc; 
Nc:Ns:Nws:Nl:Nlb:1:1/Nc - instead of one common website and one common logistician, several websites (specific to each seller) are provided as well as several specific logisticians related or not to sellers. In this case the process management schema is more complex: B2B2B2C;

Nc:Ns:1ws:Nl:Nlb:1:1/Nc - a common website for several sellers is proposed by an independent party, who can organize and dispatch collected requests and orders to appropriate logisticians, each able to provide services in his/her field of activity. In this context not only professional (business) providers can participate, but also independent actors or stakeholders from uberization point of view.

In this more complex organization we are able to examine the situation of each actor/stakeholder. He/she can be either an individual or a firm. The seller can be a shop, a supermarket or an individual farmer. For delivery activities we may also find delivery firms, subcontractors as well as individual actors. With respect to existing situations, we can observe the same difference between the Booking.com platform that brings together individual clients and accommodation firms (hotels, etc.) and the Airbnb platform that links up individual clients and individual accommodation providers. We find the same difference between the Taxi platform and the Uber platform. In our case of Box/Locker based commerce and delivery, an intermediation platform is required in order to manage the different collaboration situations identified above. Its goal is to take into account all identified collaborations between different stakeholders, who may be firms or individuals.

From a theoretical point of view we are not far from "uberization", which has two categories of actors: clients and providers at each step of the process: client choosing products proposed by seller as provider; seller as client of distribution process and logistician as provider; Box/Locker as provider for final client... During this process, several intermediations must be organized with respect to the appropriate distribution process. The goal is to connect in an individual way the former (the client) with the latter in order to find a product proposed by a provider (the seller). This can be organized in various ways: either each actor has his/her own website and the client knows how to connect to it, or someone has elaborated a common website. In the first case, each seller is responsible for his/her website, while in the second case someone has elaborated this common website. For logistic aspects, there are also several solutions: a close relationship between the seller and the logistician (his/her own one), or a complete separation between these two activities with one or more logisticians specialized in providing specific products (goods and foods) working for one or multiple sellers. With this multi-actor configuration at each step in the sales - delivery process, intermediation is required to find and assign appropriate actors (firms or individuals). This approach can be used to locate a Box/Locker in the village square and allow local producers (fruits, vegetables, meat, etc.) to sell and distribute their products in a very short, local distribution circuit, corresponding to collaborative, circular economy.

Intermediation is a very important service that must be provided to support this collaborative economy. This is because it allows creation of short distance circuits between providers and consumers, mainly clients and farmers, to shorten fruit, vegetable and meat distribution distance and time, thus allowing better quality and appropriate prices.

These situations can be summarized in Fig. 3.

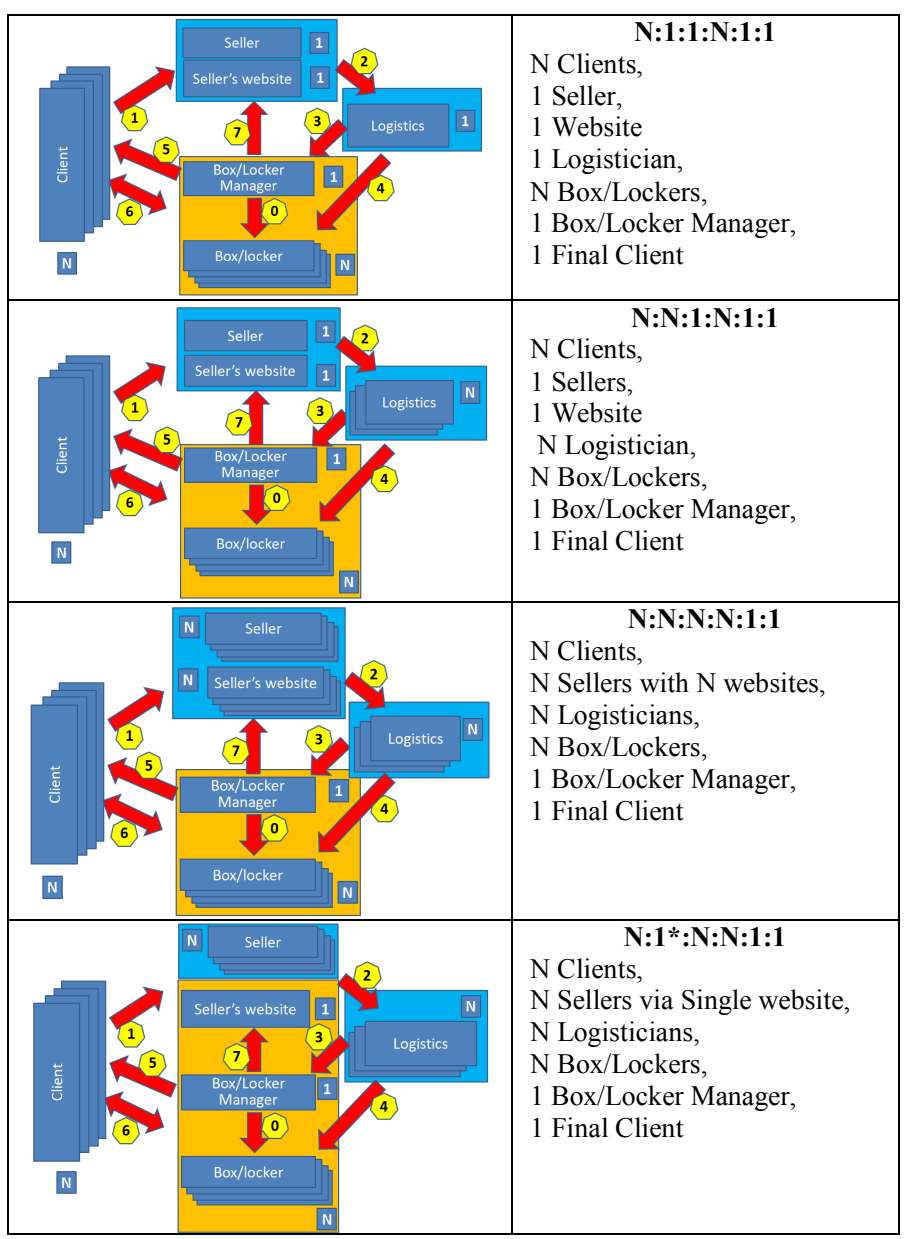

Fig. 3. Different working configurations.

\section{STUDY OF DIFFERENT POTENTIAL BEHAVOIRS}

While the generic architectural view is unique, its deployment must take into account the different working configurations discussed above. We are able to propose a number of different working conditions. However, it is not easy to determine users' preferences. Although we tried to collect potential behaviors by submitting a questionnaire to potential users, it would appear to be no easy matter to obtain tangible results. The proposed functionalities are too far from the imagination of potential users. To determine appropriate functioning, we need to create real working conditions in order to place users in this context. We can then collect their appraisals as well as time-related aspects, taking into account the observed behaviors of all parties involved, i.e. clients, sellers, logisticians and Box/Locker managers.

The main properties are as follows:

1) Client delivery time or the time required to deposit the goods/foods in the Box/Locker. Clients wish to shorten this 
time to $24 \mathrm{~h}$ for parcels, as now proposed by Amazon Premium. For foods, this time could be shortened or adapted to clients' requests.

2) Logistics, transportation and loading parameters in the selected Box/Locker with two contradictory characteristics: for the client, as mentioned above, this needs to be as soon as possible or in accordance with his/her request while, for the logistician, it is more profitable to load for several clients. The main factors involved in the optimization procedure are the distance between logistician location and the target Box/Locker and the number of parcels to load. Loading frequency is to be determined with regard to collected data: turnover of goods in the Box/Locker, average time of goods storage, loading frequency and evolution.

3) Box/Locker occupancy: This can provide us with current clients' behaviors, their promptness in retrieving their goods and the times when they forgot to retrieve them, as well as contribute to the quantitative vision and working strategies. This will allow us to appraise and increase Box/Locker profitability.

4) Main parameters: Size of the Box/Locker: 24 or 48 slots; Loading delay (time of delivery): $3 \mathrm{~h}, 6 \mathrm{~h}, 12 \mathrm{~h}, 24 \mathrm{~h}$ with discrete moments, or continuously; Cost of object/parcel stay: in relation with loading delay (same period) and possibility of penalty if longer stay; Frequency or turnover of object/parcel and frequency of loading trips; Delivery cost: distance, frequency, numbers of objects/parcels provided; Nature of objects/parcels and their storage conditions: dry, ambient, cold, frozen area.

\section{CONCLUSIONS}

In this paper we presented a new kind of Box/Locker, which is able to store foods according to their storage characteristics: ambient, fresh or frozen temperature. We dispose of a first prototype, which is a Proof of Concept of this Box/Locker. In-city tests can now start. We are not concerned only with classical use of the Box/Locker, i.e. used by one seller (shop, super or hyper market), but also and mainly with a new operational mode related to collaborative sharing economy. This means opening it up to several sellers providers, who may or may not have their own website. We propose either to aggregate these websites or to elaborate them and integrate them in the logistician process deriving from different sellers - providers. We can thus share our Box/Lockers with short circuit / distance actors, at city or town level.

Naturally, a number of important aspects need to be finalized. Top on the list is protection of each party's personal information to allow all concerned to retain their commercial advantages. Other aspects include security (avoiding vandalism, theft, etc.), traceability of all operations (loading, retrieving, etc.), not to mention the hygienic aspect (cleaning, removing perished foods, etc.) and "return to provider" conditions, definition and application (if this can be considered as applicable). From the User Interface point of view, we are currently testing two options: a classical one based on a large multi-touch screen as on other Box/Lockers, and a second one, which provides no Box/Locker interaction support and relies exclusively on the user's Smartphone screen for interaction. Consequently, user adaptability is more natural, access security is enhanced, and vandalism is reduced.

\section{ACKNOWLEDGMENT}

This work is a consortium-based project with multiple skills (mechanics, cooling system, ICT aspects). We are in charge of this last aspect. We thank our partners working on other aspects of the project for their contributions.

\section{REFERENCES}

[1] A. Caragliu, C. Del Bo and P. Nijkamp. Smart Cities in Europe. Journal of Urban Technology, vol. 18, no 2, pp. 65-82, 2011.

[2] C. Yin., Z. Xiong., H. Chen, J. Wang, D. Cooper, B. David. A literature survey on smart cities. SCIENCE CHINA, Information Sciences, October 2015, Vol. 58 100102:1-100102:18, doi: 10.1007/s11432-0155397-4, Science China Press and Springer-Verlag Berlin Heidelberg 2015 info.scichina.com link.springer.com

[3] B. David, C. Yin, Y. Zhou, T. Xu, B. ZHhang, H. Jin, R. Chalon, SMART-CITY: problematics, techniques and case studies, ICCM'2012 8th International Conference on Computing Technology and Information Management, April 24-26, 2012, Seoul, Korea

[4] Towards Innovative Freight and Logistics, Research for Innovative Transports Set - Volumes 1 \& 2, Edited by Corinne Blanquart, IFSTTAR, France, Uwe Clausen, Dortmund University, Germany, Bernard Jacob, Ecole Nationale des Travaux Publics de l'Etat, France, ISBN: 9781786300270 , ISTE - Wiley, May 2016

[5] D. Patier, B. David, V. Deslandres, R. Chalon. A new concept for urban logistics: Delivery area Booking. The Eigth International Conference on City Logistics, Eiichi Taniguchi, Russell G. Thompson ed. Bali, Indonesia. Procedia Social and Behavioral Sciences 125. Elsevier. ISSN 1877-0428, pp. 99-110, 2014.

[6] J.H.E. Andriessen, "Working with groupware: understanding and evaluating collaboration technology". Springer, CSCW Series, 2003.

[7] C. Ellis and J. Wainer, "A conceptual model of groupware", in Proceedings of CSCW'94, ACM Press, 1994, pp. 79-88.

[8] C. Ellis, S.J. Gibbs and G.L. Rein, "Groupware: some issues and experiences", in Communications of the ACM, vol. 34, $\mathrm{n}^{\circ}$ 1, 1991, pp. 38-58.

[9] B. David, R. Chalon, C. Yin. Collaborative systems \& Shared Economy (Uberization): Principles \& Case Study, The 2016 International Conference on Collaration Technologies and Systems (CTS 2016), october 31- November 4, 2016, Orlando, Florida USA

[10] S. P. Choudary, "Platform Thinking, the new rules of business in a networked world", on-line: http://platformed.info/.

[11] InPost https://inpost24.com/

[12] BingoBox \& Amazon Go https://siecledigital.fr/2017/02/21/bingoboxamazon-go-wechat/

[13] Amazon Go https://www.amazon.com

[14] Bybox https://en.wikipedia.org/wiki/ByBox

[15] Bybox https://www.bybox.com

[16] Bertrand David, René Chalon (2017), Fresh and Frozen Food Box/Lockers as part of Market, e-Market and Collaborative Economy Smart City Environment: Systemic \& logistic point of view, 6th IEEE International Conference on Advanced Logistics and Transport (IEEE ICALT 2017), 24-27 July 2017, Bali - Indonesia 